\title{
MicroRNA-125b may function as an oncogene in lung cancer cells
}

\author{
XIKAI WANG ${ }^{*}$, YANQIU ZHANG ${ }^{*}$, YANYUN FU, JUAN ZHANG, LIHONG YIN, YUEPU PU and GEYU LIANG
}

Key Laboratory of Environmental Medicine Engineering Ministry of Education, School of Public Health, Southeast University, Nanjing, Jiangsu 210009, P.R. China

Received March 25, 2014; Accepted November 21, 2014

DOI: $10.3892 / \mathrm{mmr} .2014 .3142$

\begin{abstract}
The present study aimed to investigate the biofunctions of microRNA (miR)-125b on lung cancer cells. A miR genechip array was used to examine the differential expression of miRs between 95D lung cancer cells and 16 human bronchial epithelial (HBE) cells. Overexpression of miR-125b was observed in the cell lines and in the lung carcinoma tissues compared with the adjacent tissues, confirmed using reverse transcription quantitative polymerase chain reaction. Bioinformatic analysis of miR-125b was also performed, including target prediction, gene ontology and pathway analysis. MTT, flow cytometry and Transwell assays were also used to examine the effect of downregulated miR-125b on the proliferation, apoptosis, invasive ability and cell cycle of 95D cells. Significant differences were observed in the expression of $45 \mathrm{miRs}$ in the 95D cells compared with those in 16HBE cells and the expression of miR-125b was significantly higher in 95D cells compared with that in 16HBE cells as well as in lung tumor tissues compared with that in adjacent tissues. In addition, inhibition of the expression of miR-125b in 95D cells induced apoptosis, G1/S phase arrest and reduction of their invasive ability. In addition, bioinformatics software predicted that miR-125b was involved in the regulation of several pathways associated with cancer, including the transforming growth factor- $\beta$, Wnt and mitogen-activated protein kinase signaling pathways. These data indicated for the first time, to the best of our knowledge, that miR-125b may function as an oncogene in lung cancer.
\end{abstract}

\section{Introduction}

MicroRNAs (miRs) are a series of RNAs between 14 and $20 \mathrm{nt}$ in length, which regulate the biological functions of cells by

Correspondence to: Professor Geyu Liang, Key Laboratory of Environmental Medicine Engineering Ministry of Education, School of Public Health, Southeast University, 87 Ding Jia Qiao, Nanjing, Jiangsu 210009, P.R. China

E-mail: lianggeyu@163.com

*Contributed equally

Key words: microRNA-125b, lung cancer cell, bioinformatic analysis, biological function acting on the translation of target proteins $(1,2)$. Several types of $\mathrm{miR}$ are significantly differentially expressed in tumor tissues compared with normal tissues. miR-15 and miR-16 in mononuclear cells in peripheral blood were shown to be absent or deficient among $>68 \%$ of patients with chronic lymphocytic leukemia (3). The expression of Let-7 was shown to be downregulated in lung cancer, while miR-143 and miR-145 were downregulated in colorectal cancer $(4,5)$. Therefore, it was suggested that these miRs may be closely associated with the development and progression of cancer.

Lung cancer has rapidly increasing rates of morbidity and mortality. According to a report by the World Health Organization on global rates of cancer in 2008, lung cancer had the highest rates of morbidity and mortality among different types of tumor (6). On initial diagnosis, certain patients present with tumor migration or other severe complications, resulting in poor prognosis despite appropriate treatment. Therefore, novel effective biomarkers for early diagnosis and treatment are urgently required.

Since it was demonstrated that the expression of let-7 is significantly reduced in lung cancer patients with relatively poor prognosis, evidence on the association between miRs and lung cancer has increased (4). It has also been observed that the increased expression of miR-21 induces the proliferation of cancer cells in nude mice, indicating enrichment of mRNAs encoding regulators of cell cycle checkpoints (7).

However, few studies have been performed on the expression and, in particular, the biofunctions of miR-125b in lung cancer $(8,9)$. In the present study, the expression profile of human bronchial epithelial (16HBE) cells and lung cancer (95D) cells were compared by miR microarray analysis. In addition, bioinformatic analysis was performed to analyze the putative targets of $\mathrm{miR}-125 \mathrm{~b}$ and the possible regulatory mechanism. To further examine the possible biological functions of miR-125b involved in the development and progression of lung cancer, the effects of miR-125b on the proliferation, apoptosis, cell cycle and invasive ability of the 95D cell lines were investigated. The results are the first, to the best of our knowledge, to demonstrate the function of miR-125b in lung cancer cells.

\section{Materials and methods}

Cell culture and RNA preparation. The $95 \mathrm{D}$ and $16 \mathrm{HBE}$ cells were obtained from the Chinese Academy of Sciences Type Culture Collection Cell Library Committee (Shanghai, 
China). These cells were cultured in RPMI-1640 cell culture medium supplemented with $10 \%$ fetal bovine serum (FBS; HyClone, GE Healthcare Life Sciences, Little Chalfont, UK), 100 units/ml penicillin and 100 units $/ \mathrm{ml}$ streptomycin sulfate in a humidified $5 \% \mathrm{CO}_{2}$ incubator at $37^{\circ} \mathrm{C}$. The total RNA was isolated using TRIzol reagent (Invitrogen Life Technologies, Carlsbad, CA, USA), resolved in nuclease-free water and preserved at $-80^{\circ} \mathrm{C}$.

miR microarrayanalysis. The total RNA was purified to remove any mRNA prior to sequencing. A GeneChip miRNA 2.0 array (Affymetrix, Santa Clara, CA, USA) was used to analyze the miRNA expression profile and one-way analysis of variance (ANOVA) was used to identify any significant differences among the groups. $\mathrm{P}<0.05$ was considered to indicate a statistically significant difference. A fold change $>2$ was used as the standard in identifying the differentially expressed miRs.

$m i R$ bioinformatics analysis. The prediction of target candidates of miR-125b was performed using miRGen targets on three authority target predicting software programs, TargetScan 5.1 (http://www.targetscan.org/), Pictar (http:/ pictar.mdc-berlin.de/) and miRanda (http://www.microrna. org/microrna/home.do). The miR-125b targets were then entered into the DAVID Bioinformatics Resources 6.7 software to perform Gene Ontology (GO) annotation. In addition, DIANA-miRPath software (http://diana.cslab.ece.ntua.gr/ pathways/) was used to perform online gene enrichment analysis of the miR-125b putative targets, which compared the set of miR-125b targets to all known Kyoto Encyclopedia of Genes and Genomes (KEGG; http://www.kegg.jp/) pathways. Subsequently, the information containing the numbers and P-values, in the form 'In (P-value)', of the enrichment genes in the specific pathways were examined. The interaction and reaction networks between the genes were also analyzed according to the pathway data provided by the KEGG pathway database.

Transfection of anti-miR-125b. The transfections were performed using siPORT NeoFX transfection reagent (Invitrogen Life Technologies) according to the manufacturer's instructions. The cells were trypsinized at the logarithmic growth period and were resuspended in normal growth medium at $1 \times 10^{5}$ cells $/ \mathrm{ml}$. The siPORT NeoFX transfection reagent was diluted (1:30) in Opti-MEM I (Invitrogen Life Technologies) and incubated for $10 \mathrm{~min}$ at room temperature. Subsequently, anti-miR-125b (Invitrogen Life Technologies) and anti-negative control (Anti-miR ${ }^{\mathrm{TM}}$ Negative Control \#1, AM17010; Invitrogen Life Technologies) were diluted in Opti-MEM I. The transfection reagents were mixed and incubated at room temperature for $10 \mathrm{~min}$. The transfection complexes were dispensed into the empty wells of a six-well culture plate. The cells were added to the transfection complexes and were incubated at $37^{\circ} \mathrm{C}$ for $24 \mathrm{~h}$. Following transfection, reverse transcription quantitative polymerase chain reaction (RT-qPCR) was performed to examine the expression levels in the miR-125b-transfected cells and to confirm the transfection efficiency. RT-qPCR analyses for miR-125b were performed using TaqMan microRNA assays (Applied Biosystems Life Technologies, Foster City, CA, USA).All reagents, primers and probes were obtained from Applied Biosystems. The $15 \mu \mathrm{l}$ RT reaction consisted of $7 \mu \mathrm{l}$ Master mix (100 mM dNTPs (with dTTP) $0.15 \mu \mathrm{l}$; MultiScribe ${ }^{\mathrm{TM}}$ Reverse Transcriptase, $50 \mathrm{U} /$ $\mu 11.00 \mu \mathrm{l}$; 10X Reverse Transcription buffer $1.50 \mu \mathrm{l}$; RNase Inhibitor, $20 \mathrm{U} / \mu \mathrm{l} 0.19 \mu \mathrm{l}$; Nuclease-free water $4.16 \mu \mathrm{l}$ ), $3 \mu \mathrm{l}$ stem-loop RT primer (ID 000449), and $5 \mu$ l RNA sample. The reactions were incubated on ice for $5 \mathrm{~min}$ and followed by $1^{\circ} \mathrm{C}$ for $30 \mathrm{~min}, 42^{\circ} \mathrm{C}$ for $30 \mathrm{~min}, 85^{\circ} \mathrm{C}$ for $5 \mathrm{~min}$ and held in $4^{\circ} \mathrm{C}$. The $20 \mu \mathrm{l}$ PCR reaction included product from RT reaction (minimum 1:15 dilution) $1.33 \mu \mathrm{l}$; TaqMan MicroRNA assay (20X) $1.00 \mu \mathrm{l}$ (ID 000449); TaqMan 2X Universal PCR Master mix, No AmpErase UNGa $10.00 \mu \mathrm{l}$; Nuclease-free water $7.67 \mu 1$. Amplification was performed using the Step One Plus Detection System (Applied Biosystems), and initiated at $95^{\circ} \mathrm{C}$ for $10 \mathrm{~min}$, followed by 40 cycles of denaturation at $95^{\circ} \mathrm{C}$ for $15 \mathrm{sec}, 60^{\circ} \mathrm{C}$ for $1 \mathrm{~min}$ and annealing and extension at $60^{\circ} \mathrm{C}$ for $1 \mathrm{~min}$.

Detection of cell proliferation. An MTT assay was used to determine the cell proliferation. The cells $\left(1 \times 10^{4}\right)$ were seeded into each well of a 96-well plate. The cells were transfected in triplicate wells with $50 \mathrm{nM}$ anti-miR-125b or anti-miR negative control and were cultured in complete culture medium for $48 \mathrm{~h}$. The culture supernatants were then removed and $200 \mu \mathrm{l}$ MTT solution $(0.5 \mathrm{mg} / \mathrm{ml}$; Amresco LLC, Solon, OH, USA) was added to each well, followed by incubation for $4 \mathrm{~h}$ at $37^{\circ} \mathrm{C}$. The supernatants were then removed and $150 \mu \mathrm{l}$ dimethyl sulfoxide (Sigma-Aldrich) was added into each well and agitated to dissolve the formazan crystals. The optical density (OD) was measured at $570 \mathrm{~nm}$ in an automatic enzyme standard microtiter plate reader (MRX; Dynex Technologies, Chantilly, VA, USA) . The experiment was repeated three times.

Detection of cell apoptosis. The cells were analyzed for annexin $\mathrm{V}$ binding and propidium iodide (PI) incorporation to distinguish between apoptotic and necrotic cells. Cells $\left(3 \times 10^{5}\right)$ were seeded into each well of a 96-well plate and transfected in triplicate wells with $50 \mathrm{nM}$ anti-miR-125b or anti-miR negative control, followed by culture in complete culture medium for $48 \mathrm{~h}$. The cells were harvested, washed twice in ice-cold PBS, resuspended in $500 \mu 1$ binding buffer and stained for $30 \mathrm{~min}$ with Annexin V-fluorescein isothiocyanate and PI. The stained cells were analyzed using a flow cytometer (TY4124; BD Technologies, Durham, NC, USA) at an excitation wavelength of $488 \mathrm{~nm}$ and emission wavelength of $525 \mathrm{~nm}$ for fluorescein isothiocyanate fluorescence and $610 \mathrm{~nm}$ for PI fluorescence. The experiment was repeated three times.

Cell cycle analysis. The cells $\left(3 \times 10^{5}\right)$ were seeded into each well of a 96-well plate and transfected in triplicate wells with $50 \mathrm{nM}$ anti-miR-125b or anti-miR negative control, followed by culture in complete culture medium for $48 \mathrm{~h}$. The cells were harvested, washed in ice-cold PBS and fixed with $70 \%$ ice-cold ethanol for $24 \mathrm{~h}$. Subsequently, the cells were resuspended in $100 \mu \mathrm{l}$ RNase and cultured for $30 \mathrm{~min}$ at $37^{\circ} \mathrm{C}$. The suspension was mixed with $400 \mu \mathrm{l}$ PI for $30 \mathrm{~min}$ in the dark and the stained cells were analyzed using a flow cytometer at an excitation wavelength of $488 \mathrm{~nm}$ and $610 \mathrm{~nm}$ for PI fluorescence. The experiment was repeated three times. 
Table I. KEGG pathway analysis of the putative targets of microRNA-125b.

\begin{tabular}{lcc}
\hline KEGG pathway & KEGG pathway ID & -In (P-value) \\
\hline Transforming growth factor- $\beta$ signaling pathway & hsa04350 & 5.85 \\
Renin-angiotensin system & hsa04614 \\
Parkinson's disease & hsa05020 & 5.20 \\
Renin-angiotensin system & hsa00602 \\
Polyunsaturated fatty acid biosynthesis & hsa01040 \\
Pancreatic cancer & hsa05212 \\
Notch signaling pathway & hsa04330 \\
Wnt signaling pathway & $\mathrm{hsa04310}$ & 3.95 \\
Glycan structures-biosynthesis 2 & $\mathrm{hsa} 01031$ & 3.95 \\
N-Glycan biosynthesis & $\mathrm{hsa} 00510$ & 3.72 \\
\end{tabular}

KEGG, Kyoto Encyclopedia of Genes and Genomes; hsa, Homo sapiens.

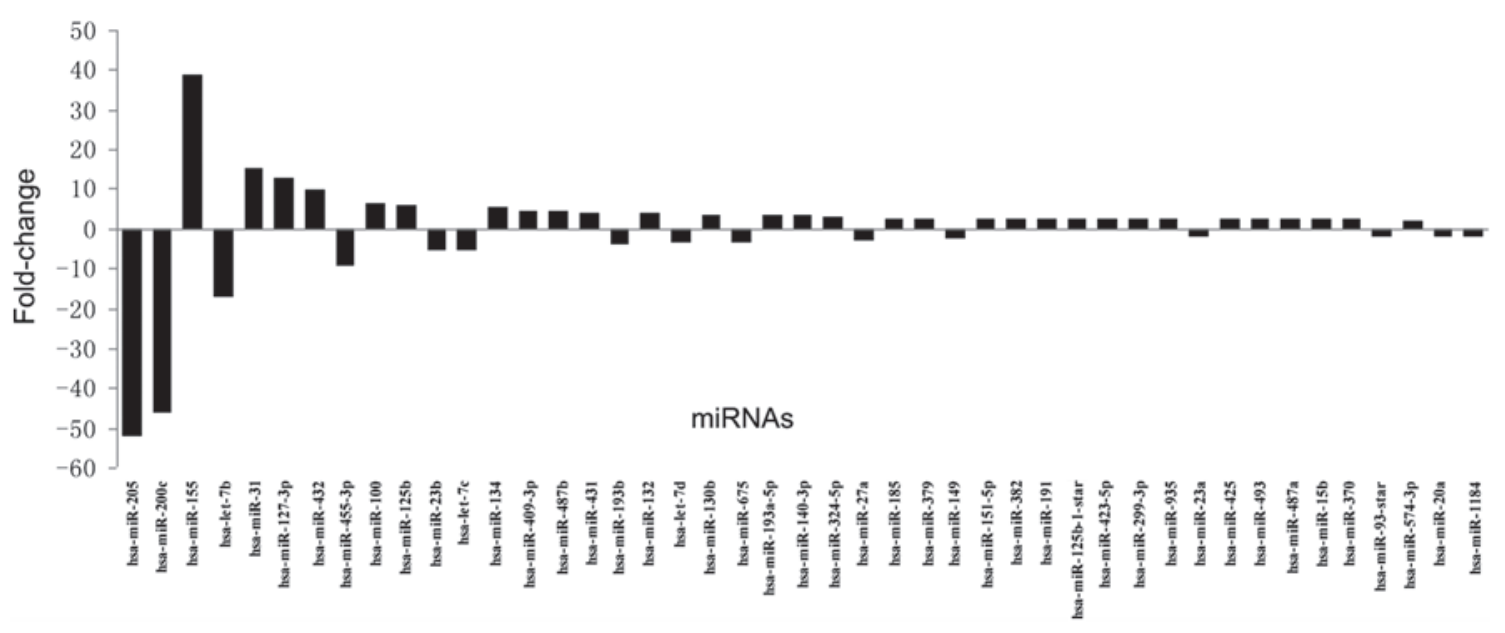

Figure 1. Fold-changes of the dysregulated miRNAs of the 95D cells compared with the 16HBE cells. miRNA, microRNA; hsa, Homo sapiens.

Detection of cell invasion. Matrigel was thawed at $4^{\circ} \mathrm{C}$ overnight and then diluted $(5 \mathrm{mg} / \mathrm{ml})$ in serum-free cold RPMI-1640 (Corning Inc., Corning, NY, USA) at a dilution of 1:8 and was transferred into the upper chamber of a 24-well Transwell system (100 $\mu \mathrm{l}$ in each well). The Transwell was incubated at $37^{\circ} \mathrm{C}$ for $\sim 2-3 \mathrm{~h}$ for gelling. Subsequently, $100 \mu \mathrm{l}$ cell serum-free RMPI-1640 suspension containing $1 \times 10^{4}$ anti-miR-125b-transfected cells were added to the Matrigel. The lower chamber of the Transwell was filled with $600 \mu 1$ RPMI-1640 containing $10 \% \mathrm{FBS}$. The 24 -well plate was incubated at $37^{\circ} \mathrm{C}$ for 20-24 h. The cells which did not invade and remained in the upper chamber of the Transwell were removed by washing with PBS. Subsequently, 4\% paraformaldehyde was used to immobilize the cells that had invaded the lower chamber and hematoxylin and eosin staining was performed. The cells in the lower chamber of the Transwell were counted under a light microscope (magnification, x400; BX41; Olympus Corp., Tokyo, Japan). The experiment was repeated three times.

Statistical analysis. Statistical analyses were performed using SPSS 13.0 software (SPSS, Inc., Chicago, IL, USA). Values are expressed as the mean \pm standard deviation. Analysis of variance and Dunnet's test were performed to compare the differences between the exposure group and the control group. $\mathrm{P}<0.05$ was considered to indicate a statistically significant difference.

\section{Results}

Gene chip analysis of miRs in 95D cells compared with those in $16 H B E$ cells. Gene chip analysis revealed that $45 \mathrm{miRs}$ were significantly differently expressed in the 95D cells compared with the $16 \mathrm{HBE}$ cells, of which 30 were upregulated and 15 were downregulated. The fold-changes in the dysregulated miRs are shown in Fig. 1. Confirmation of the expression of miR-125b by RT-qPCR supported the results of the gene chip analysis (data not shown).

Bioinformatic analysis of miR-125b. Analysis was performed using miRGen Target software, which involved the prediction of possible targets of miR-125b by TargetScan, Pictar and miRanda. A total of 72 genes were identified as possible putative targets of miR-125b (data not shown). The GO terms of the biological process were further analyzed, 
Table II. Effect of downregulated miR-125b on 95D cell proliferation.

Group

Optical density

Blank

$0.884 \pm 0.019$

Anti-negative control-transfected

$0.869 \pm 0.010$

Anti-miR-125b-transfected

$0.892 \pm 0.008$

Values are expressed as the mean \pm standard deviation. miR, microRNA.

A

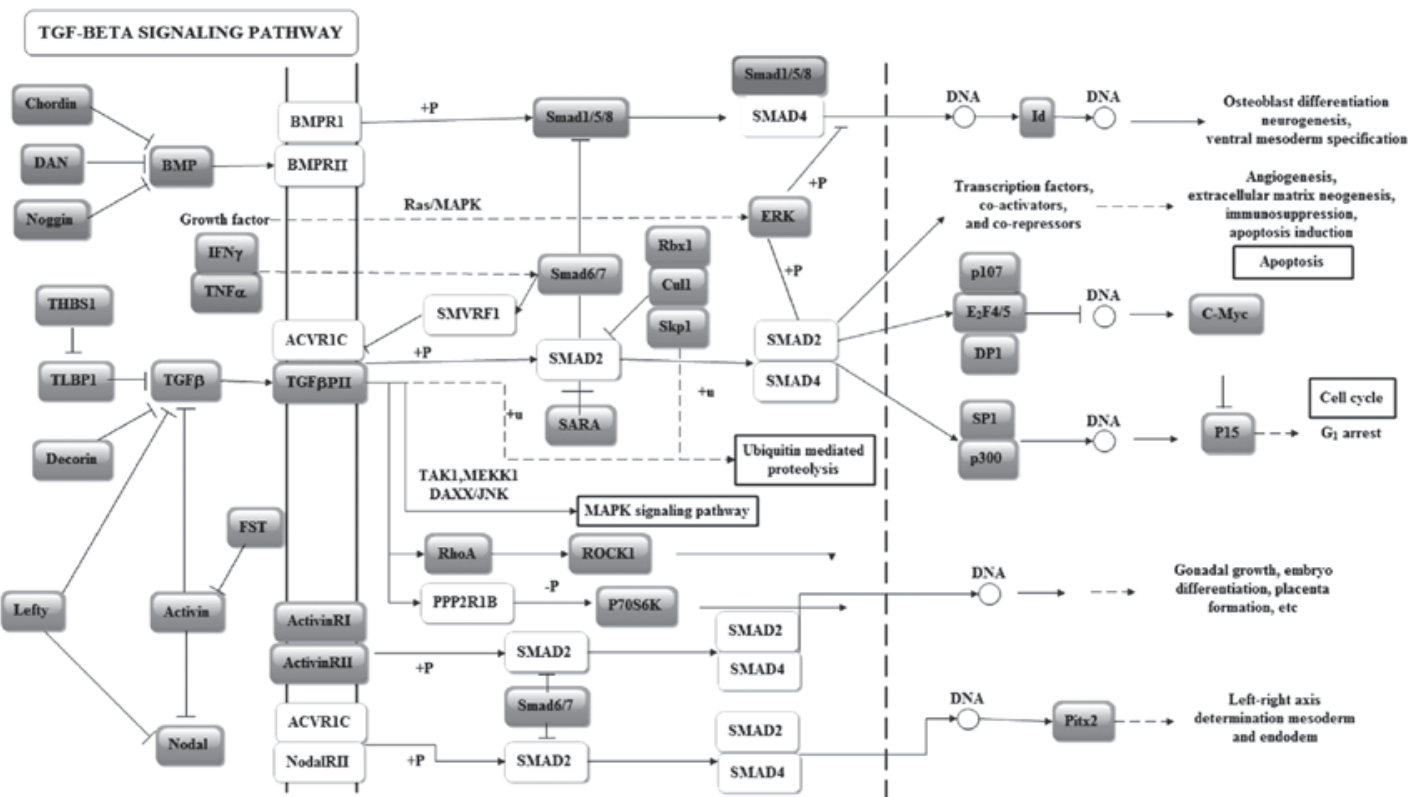

B

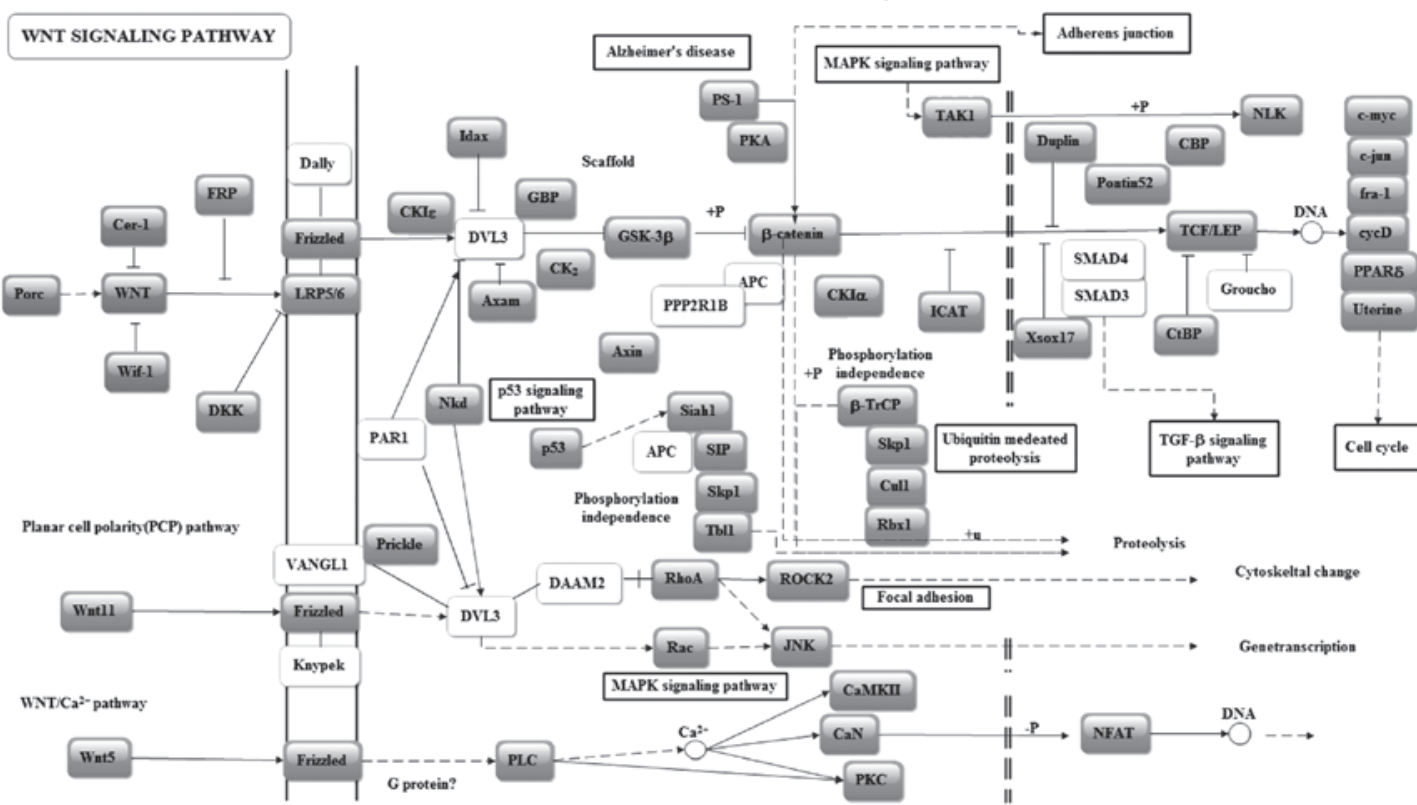

Figure 2. Regulation of miR-125b on the (A) TGF- $\beta$ signaling and the (B) Wnt signaling KEGG pathways. Potential targets of miR-125b are outlined in bold. KEGG, Kyoto Encyclopedia of Genes and Genomes; TGF- $\beta$, transforming growth factor- $\beta$; MAPK, mitogen-activated protein kinase; JNK, c-Jun N-terminal kinase; APC, adenomatous polyposis coli; PPP2R1B, protein phosphatase 2, regulatory subunit A $\beta$.

revealing 21 associated functional annotations. The results demonstrated that terms associated with the function of phosphorylation, including the phosphate metabolic process and protein amino acid phosphorylation, were annotated by several gene targets of miR-125b. Stress-associated terms were also annotated by several targets. Of note, among the 21 terms, the term 'regulation of MAP kinase kinase kinase (MAP3K) cascade' was found (data not shown). 
Table III. Effect of downregulated miR-125b on the apoptotic rate of 95D cells.

Group

Apoptotic rate $(\%)$

Blank

$15.92 \pm 0.99$

Anti-negative control-transfected

$16.39 \pm 1.11$

Anti-miR-125b-transfected

$20.96 \pm 0.71^{\text {a }}$

Positive $\left(0.1 \% \mathrm{H}_{2} \mathrm{O}_{2}\right)$

$30.42 \pm 2.50^{\mathrm{a}}$

${ }^{a} \mathrm{P}<0.05$, compared with the anti-negative control-transfected group. miR, microRNA.

Table IV. Effect of downregulated miR-125b on the cell cycle of 95D cells.

\begin{tabular}{llll}
\hline Group & G1 $(\%)$ & S $(\%)$ & G2 $(\%)$ \\
\hline Blank & $15.91 \pm 0.71$ & $58.33 \pm 1.71$ & $25.75 \pm 2.07$ \\
Anti-negative control-transfected & $15.24 \pm 2.33$ & $57.54 \pm 1.43$ & $27.22 \pm 1.51$ \\
Anti-miR-125b transfected & $18.27 \pm 0.17^{\mathrm{a}}$ & $53.86 \pm 0.82^{\mathrm{a}}$ & $27.87 \pm 0.95$
\end{tabular}

${ }^{a} \mathrm{P}<0.05$, compared with the anti-negative control-transfected group. miR, microRNA.

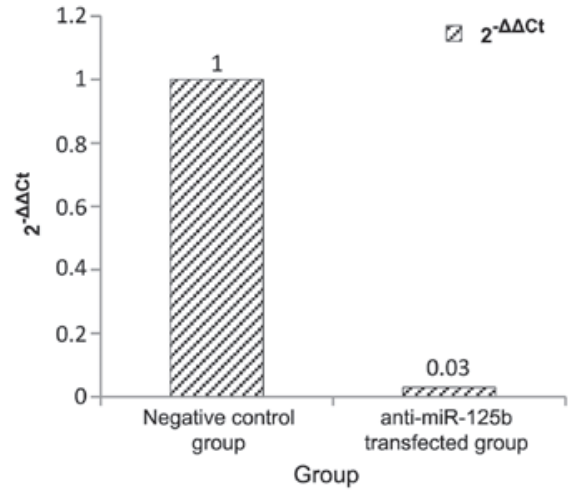

Figure 3. Identification of the miR-125b transfection efficiency in the 95D cells. miR, microRNA.

In the KEGG pathway analysis, the transforming growth factor (TGF)- $\beta$ signaling pathway scored highest (5.85). The Wnt signaling pathway, closely associated with the development and progression of cancer, also scored highly in the miR-125b enrichment pathway analysis (Table I). To further examine the impact of miR-125b on important pathways, pathway graphs, indicating the regulatory sites and interactions, were analyzed. In the TGF- $\beta$ KEGG pathway graph, several genes at key sites were found to be potentially regulated by miR-125b. ACVR1C is involved in activating the TGF- $\beta$ receptor and transmitting the signal to SMAD2, which affects cell apoptosis and cell cycle by activating a series of transcription factors (Fig. 2A). In the Wnt signaling KEGG pathway graph, DVL3, a possible target gene of miR-125b, regulates the mitogen-activated protein kinase (MAPK)-c-Jun N-terminal kinase (JNK) apoptotic process. APC and PPP2R1B affect the adherence and junctions between cells by regulating $\beta$-actin and are associated with migration and invasion (Fig. 2B).
miR-125b transfection in $95 \mathrm{D}$ cells. Following anti-miR-125b transfection, miR-125b levels were significantly inhibited to $3 \%$ of those in the negative control (Fig. 3).

Effect of anti-miR-125b on the morphology and proliferation of $95 \mathrm{D}$ cells. Under light microscopy, no significant differences were observed in the morphology or density of the anti-miR-125b-transfected 95D cells compared with those of the cells in the negative control group. The MTT assay, used to examine the effect of miR-125b downregulation on the viability of the 95D cells, demonstrated no significant differences in the OD values among the groups ( $\mathrm{P}>0.05$; Table II).

Apoptosis of anti-miR-125b-transfected 95D cells. PI and Annexin $\mathrm{V}$ were used to stain the $95 \mathrm{D}$ cells and the apoptotic rate was determined using flow cytometry. No significant difference was observed between the blank and the negative control groups $(\mathrm{P}>0.05)$. The apoptotic rate of the cells in the positive group was significantly higher than that of cells in the other groups $(\mathrm{P}<0.05)$. Of note, the apoptotic rates of the cells with downregulated miR-125b were significantly higher compared with those in the negative control group $(\mathrm{P}<0.05$; Fig. 4 and Table III).

Cell cycle analysis of anti-miR-125b-transfected 95D cells. The cell cycle of anti-miR-125b-transfected 95D cells was assessed using flow cytometry. The results demonstrated that downregulation of miR-125b in the 95D cells induced G1/S phase arrest compared with the negative group $(\mathrm{P}<0.05$; Fig. 5 and Table IV).

Invasive ability of the anti-miR-125b-transfected $95 D$ cells. A Transwell assay was used to evaluate the impact of downregulated miR-125b on the invasive ability of 95D cells. No significant change was observed in the number of invaded cells between the negative control group and the blank group $(\mathrm{P}>0.05)$. However, 

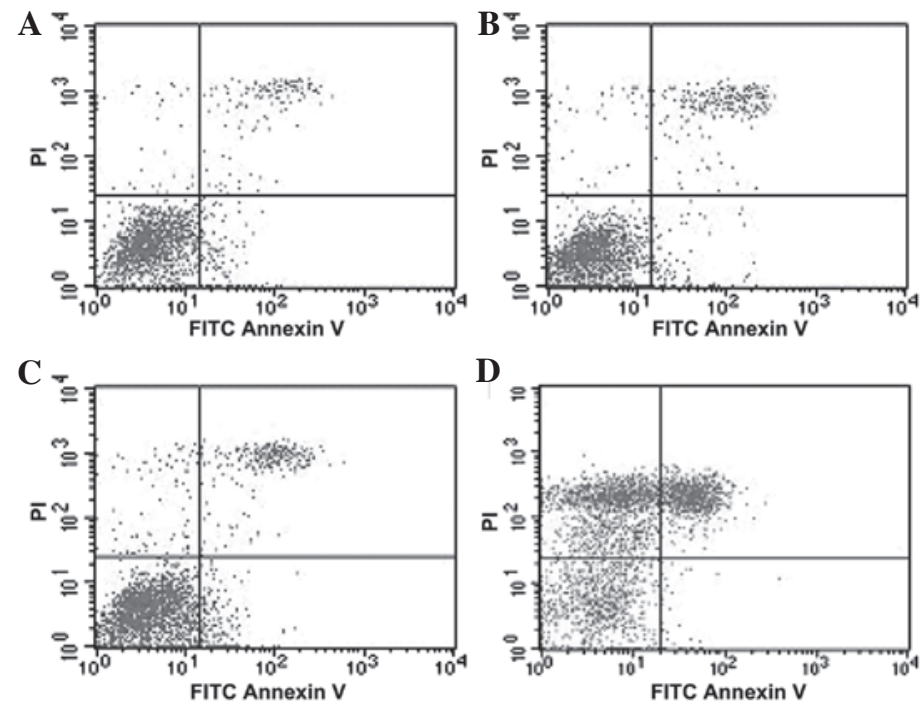

Figure 4. Effect of downregulated miR-125b on the apoptotic rate of the 95D cells. (A) Blank group; (B) anti-negative control-transfected group; (C) anti-miR-125b transfected group; (D) positive group. FITC, fluorescein isothiocyanate; PI, propidium iodide; miR, microRNA.

A

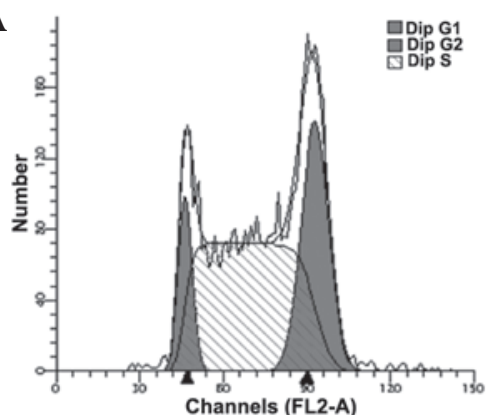

B

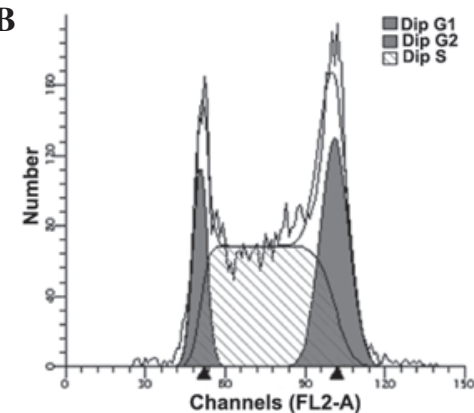

C

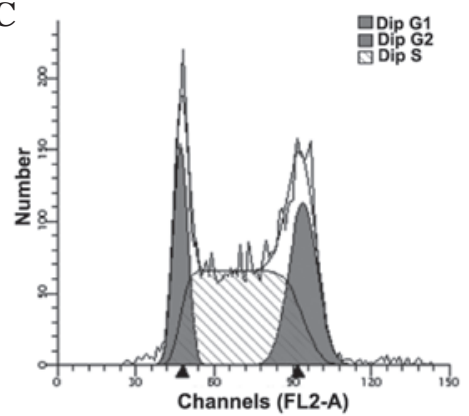

Figure 5. Effect of downregulated miR-125b on the cell cycle of the 95D cells. (A) Blank group; (B) anti-negative control-transfected group; (C) anti-miR-125b-transfected group. miR, microRNA; Dip G1, G1 phase; Dip G2, G2 phase; Dip S, S phase.

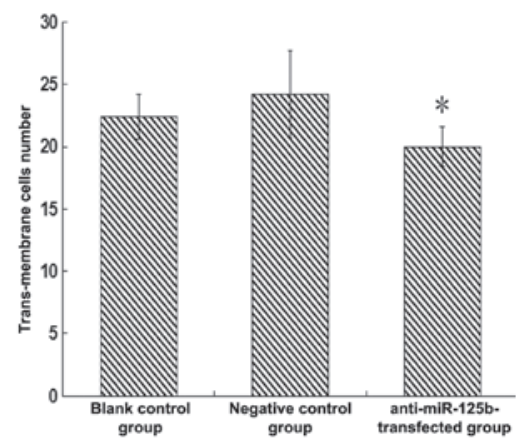

Figure 6. Effect of downregulated miR-125b on the invasive ability of 95D cells. miR, microRNA. "P<0.05 compared with the negative control group.

the number of invaded cells in the anti-miR-125b-transfected group was significantly lower compared with that in the negative control group $(\mathrm{P}<0.05$; Fig. 6).

\section{Discussion}

In the present study, the expression of miR-125b was observed to be significantly increased in lung cancer cells and inhibition of miR-125b had marked effects on several biological processes of lung cancer, including apoptosis, cell cycle and invasion ability. Inhibition of the expression of miR-125b in the 95D cell line induced an increase in the apoptotic rate, caused G1/S-arrest and reduced the invasive ability of the cells. These three aspects are well known to be associated with tumor development (10-12). During the development of cancer, the apoptotic mechanism is dysregulated to a certain extent, which reduces the number of apoptotic cells. The invasive ability is increased, improving the migration of cancer cells and the cell cycle is also affected, with an increased number of cells in the S phase (DNA duplication phase) of the cell cycle (13). The results of the present study also demonstrated that the deregulation of miR-125b resulted in almost the opposite of an oncogenic effect, suggesting that miR-125b may have an oncogenic function. These results are the first, to the best of our knowledge, to elucidate the functions of miR-125b in lung cancer.

The target prediction indicated 72 genes as potential targets of miR-125b and, by clustering these 72 genes, GO annotation and KEGG pathway analysis were performed. The results demonstrated that miR-125b may be associated with TGF- $\beta$ to stimulate cancer growth. It has been previously suggested that TGF- $\beta$ is an effective factor in regulating cell growth, division 
and migration (14), and that TGF- $\beta$ is overexpressed in lung cancer and can promote the malignant transformation, invasion and migration of lung cancer, acting as an oncogene (15). The potential activation of TGF- $\beta$ by miR- $125 \mathrm{~b}$ observed in the present study may indicate that miR-125b has a possible cancer promoting role.

The present study also demonstrated that miR-125b is involved in the MAPK signaling pathway, which is another important cancer-associated pathway. KRAS, which is the key protein in the RAS/RAF/MAPK process, regulates cell proliferation, cell division and cell cycle, thus affecting the transformation and development of cancer $(16,17)$. The association between kRAS and lung cancer has been confirmed by several studies (18). Several previous studies on MAP3K have suggested that MAP3K not only regulates apoptosis, but also affects the proliferation and invasion of cancer cells in the development of cancer $(19,20)$. In addition, activation of JNK1 and JNK2 by the MAP3K family, which can phosphorylate nuclear factor- $\kappa \mathrm{B}$ inhibitors, may promote cancer cell growth (21). The results of the present study indicated the possible function of miR-125b in cell proliferation, cell apoptosis and cell cycle and this hypothesis was supported by the involvement of miR-125b in regulating the Wnt signaling pathway, concerning $\beta$-catenin. The Wnt signaling pathway, which regulates apoptosis, metabolism and other biological processes, is also associated with the progression of cancer (22). To briefly summarize, miR-125b may act on several cancer-associated pathways by regulating several potential targets, to promote the development of lung cancer.

These results provide support for the cancer-promoting role of miR-125b in the progression of lung cancer. Although the function of miR-125b in lung cancer has not been reported, several studies of other types of tumor have reported miR-125b to function as an oncogenic or tumor-suppressive miR.

In colorectal cancer, prostate carcinoma and leukemia, miR-125b has been recognized as an oncogenic factor. These studies found that upregulated miR-125b stimulated the growth of HT29 colorectal cancer cells by inhibiting the expression of p53 (10). Shi et al (23) found that high expression levels of miR-125b can inhibit cell apoptosis in prostate tumors by downregulating B-cell lymphoma 2 (BCl-2)-antagonist/killer 1 , a member of the Bcl-2 family and in prostate carcinoma, miR-125b improves cell growth (11). A previous study on miR-125b in human U343 and U251 glioma cells revealed that the overexpression of miR-125b can inhibit cell apoptosis by reducing the levels of Bcl-2-modifying factor, a pro-apoptotic protein (24). These results indicated that miR-125b functions as an oncogene, which mirror those of the present study. However, certain studies have observed that the function of miR-125b was opposite of that of a tumor suppressor gene. In a study investigating the impact of miR-125b on SKBR 3 breast carcinoma cells, miR-125b inhibited cell proliferation (25). In another study on hepatocellular carcinoma, the proliferative and clone forming ability of hepatoma carcinoma cells were reduced and S-phase arrest was observed (26) in cells with low expression levels of miR-125b. Therefore, the functions of miR-125b differed in various types of tumor, suggesting different regulatory mechanisms of miR-125b. In lung cancer, the regulatory mechanisms of the oncogenic effects of miR- $125 \mathrm{~b}$ require further investigation.
In conclusion, the present study was the first to investigate the biological functions of miR-125b in lung cancer and, to the best of out knowledge, to demonstrate that suppression of miR-125 expression induced apoptosis, G1/S phase arrest and, to a certain extent, inhibited the invasive ability of lung cancer cells. This may be involved in the regulation of several potential targets at the key sites of TGF- $\beta$, MAPK, Wnt and other important cancer-associated signaling pathways. By identifying the expression and the functions of miR-125b in $95 \mathrm{D}$ cells, the present study hypothesized that miR-125b may have an oncogenic role in the development and progression of lung cancer. Further investigation is required to identify the accurate targets of miR- $125 \mathrm{~b}$ and the active sites in those significant pathways.

\section{Acknowledgements}

This study was supported by the National Natural Science Foundation of China (nos. 81472939 and 81172618), the Qing Lan Project (no. 2012), the 333 project of Jiangsu Province (no. 2012), the Liu Da Ren Cai Gao Feng Project of Jiangsu Province (no. 2013-WSW-053) and the Fundamental Research Funds for the Central Universities (no. 2013).

\section{References}

1. Lee RC, Feinbaum RL and Ambros V: The C. elegans heterochronic gene lin-4 encodes small RNAs with antisense complementarity to lin-14. Cell 75: 843-854, 1993.

2. Reinhart BJ, Slack FJ, Basson M, Pasquinelli AE, Bettinger JC Rougvie AE, Horvitz HR and Ruvkun G: The 21-nucleotide let-7 RNA regulates developmental timing in Caenorhabditis elegans. Nature 403: 901-906, 2000.

3. Calin GA, Dumitru CD, Shimizu M, Bichi R, Zupo S, Noch E, Aldler H, Rattan S, Keating M, Rai K, Rassenti L, Kipps T, Negrini M, Bullrich F and Croce CM: Frequent deletions and down-regulation of microRNA genes miR15 and miR16 at 13q14 in chronic lymphocytic leukemia. Proc Natl Acad Sci USA 99: 15524-15529, 2002.

4. Takamizawa J, Konishi H, Yanagisawa K, Tomida S, Osada H, Endoh H, Harano T, Yatabe Y, Nagino M, Nimura Y, Mitsudomi T and Takahashi T: Reduced expression of the let-7 microRNAs in human lung cancers in association with shortened postoperative survival. Cancer Res 64: 3753-3756, 2004.

5. Michael MZ, O'Connor SM, van Holst Pellekaan NG, Young GP and James RJ: Reduced accumulation of specific microRNAs in colorectal neoplasia. Mol Cancer Res 1: 882-891, 2003.

6. Ferlay J, Shin HR, Bray F, Forman D, Mathers C and Parkin DM: Estimates of worldwide burden of cancer in 2008: GLOBOCAN 2008. Int J Cancer 127: 2893-2917, 2010.

7. Frezzetti D, De Menna M and Zoppoli P: Upregulation of miR-21 by Ras in vivo and its role in tumor growth. Oncogene 30: 275-286, 2011.

8. Yuxia M,Zhennan T and Wei Z: Circulating miR-125b is a novel biomarker for screening non-small-cell lung cancer and predicts poor prognosis. J Cancer Res Clin Oncol 138: 2045-2050, 2012.

9. Li Y, Chao Y, Fang Y, Wang J, Wang M, Zhang H, Ying M, Zhu $\mathrm{XX}$ and Wang HF: MTA1 promotes the invasion and migration of non-small cell lung cancer cells by downregulating miR-125b. J Exp Clin Cancer Res 32: 33, 2013.

10. Nishida N, Yokobori T, Mimori K, Sudo T, Tanaka F, Shibata K, Ishii H, Doki Y, Kuwano H and Mori M: MicroRNA miR-125b is a prognostic marker in human colorectal cancer. Int J Oncol 38: 1437-1443, 2011.

11. Pang Y, Young CY and Yuan H: MicroRNAs and prostate cancer. Acta Biochim Biophys Sin (Shanghai) 42: 363-369, 2010.

12. Bousquet M, Harris MH, Zhou B and Lodish HF. MicroRNA miR-125b causes leukemia. Proc Natl Acad Sci USA 107: 21558-21563, 2010. 
13. Dang XM, Ma AQ, Yang L, Hu H, Zhu B, Shang D, Chen TJ and Luo Y: MicroRNA-26a regulates tumorigenic properties of EZH2 in human lung carcinoma cells. Cancer Genet 205: 113-123, 2012.

14. Derynck $R$ and Zhang YE: Smad-dependent and Smad-independent pathways in TGF- $\beta$ family signaling. Nature 425: 577-584, 2003.

15. Bacon AL, Farrington SM and Dunlop MG: Mutation frequency in coding and non-coding repeat sequences in mismatch repair deficient cells derived from normal human tissue. Oncogene 20: 7464-7471, 2001.

16. Johnson GL and Lapadat R: Mitogen activated protein kinases pathways mediated by ERK, JNK, and p38 protein kinases. Science 298: 1911-1912, 2002.

17. Stacey DW: Cyclin D1 serves as a cell cycle regulatory switch in actively proliferating cells. Curr Opin Cell Biol 15: 158-163, 2003.

18. Kranenburg O, Gebbink MF and Voest EE: Stimulation of angiogenesis by Ras proteins. Biochim Biophys Acta 1654: 23-37, 2004

19. Wagner EF and Nebreda AR: Signal integration by JNK and p38 MAPK pathways in cancer development. Nat Rev Cancer 9: 537-549, 2009.

20. Weston CR and Davis RJ: The JNK signal transduction pathway. Curr Opin Cell Biol 12: 14-21, 2002.
21. Cheung PC, Campbell DG, Nebreda AR and Cohen P: Feedback control of the protein kinase TAK1 by SAPK2a/p38 $\alpha$. EMBO J 22: 5793-5805, 2003.

22. Van SM, Randall J., Sorgew A, Williams LM, Tennis M and Winn RA: Wnt signaling pathway and lung disease. Transl Res 151: 175-180, 2008.

23. Shi XB, Xue L, Yang J, Ma AH, Zhao J, Xu M, Tepper CG, Evans CP, Kung HJ and deVere White RW: An androgen-regulated miRNA suppresses Bak1 expression and induces androgen-independent growth of prostate cancer cells. Proc Natl Acad Sci USA 104: 19983-19988, 2007.

24. Xia HF, He TZ, Liu CM, Cui Y, Song PP, Jin XH and Ma X: MiR-125b expression affects the proliferation and apoptosis of human glioma cells by targeting Bmf. Cell Physiol Biochem 23: 347-358, 2009

25. Scott GK, Goga A, Bhaumik D, Berger CE, Sullivan CS and Benz CC: Coordinate suppression of ERBB2 and ERBB3 by enforced expression of micro-RNA miR-125a or miR-125b. J Biol Chem 282: 1479-1486, 2007.

26. Liang L, Wong CM, Ying Q, Fan DN, Huang S, Ding J, Yao J, Yan M, Li J, Yao M, Ng IO and He X: MicroRNA-125b suppresses human liver cancer cell proliferation and metastasis by directly targeting oncogene LIN28B2. Hepatology 52: 1731-1740, 2010. 